\title{
Büyük Ölçekli Elektrik Kesintilerinin İncelenmesi
}

\author{
Özge TUTTOKMAĞI*, Asım KAYGUSUZ \\ İnönü Üniversitesi, Elektrik-Elektronik Mühendisliği, Malatya \\ (ORCID: 0000-0002-8488-627X) (ORCID: 0000-0003-2905-1816)
}

\begin{abstract}
$\ddot{O} z$
Günümüzde modern toplum yapısındaki değişimler ve teknolojideki gelişmelerle birlikte elektrik enerjisi vazgeçilmez bir kavram haline gelmiş̧ir. Elektrik enerjisinin hemen hemen her sektörde yaygın bir şekilde kullanılması beraberinde enerjiye olan talebin her geçen gün sürekli olarak artmasına dolayısıyla da enerji talebinin karşılanmasında mevcut güç sistemleri yetersiz kalmasına neden olmaktadır. Bu durumun üstesinden gelebilmek için güç sistemlerine eklenen yeni üretim ve teknoloji birimleri mevcut sistemleri daha karmaşık hale getirmektedir. Dahası enerji talebindeki artışın durdurulamaz olması sistemin maksimum kararlılık sınırında çalışmasına neden olmaktadır. Yaşanılan bu durumlar ise güç sisteminin bazı zorluklarla karşılaşma olasılığını arttırmaktadır. Güç sistemleri için yaşanabilecek en büyük zorluk ise son yıllarda dünyada çok sık meydana gelen elektrik kesintileridir. İnsan yaşamının hem sosyal hem de ekonomik olarak ciddi şekilde etkilenmesine neden olan kesintilerin, neden-sonuçlarıyla iyi bir şekilde analiz edilmesi, gerekli düzenlemelerin yapılarak yaşanabilecek kesintileri ve etkilerini en aza indirgemesini sağlaması açısından son derece önemlidir. Yaptığımız bu çalışmada hem dünyada hem de Türkiye'de meydana gelen elektrik kesintilerinin nedenleri, etki alanları ve alınabilecek önlemler hakkında bilgi verilmiştir. Ayrıca örnek güç sistemi üzerinden kesinti analizleri yapılmıştır.
\end{abstract}

Anahtar kelimeler: Güç Sistem Analizi, Elektrik Kesintisi, Güç Sistemi Güvenilirliği, Akıllı Şebekeler.

\section{Investigation of Large Scale Power Blackouts}

\begin{abstract}
Today, with the changes in modern social structure and the developments in technology, electric energy has become an indispensable concept. The widespread use of electricity in almost every sector leads to an everincreasing demand for energy and thus to the inadequacy of existing power systems to meet energy demand. To overcome this situation, new generation and technology units added to power systems make existing systems more complex. Moreover, the unstoppable increase in energy demand causes the system to operate at the maximum stability limit. These situations increase the likelihood that the power system will encounter some difficulties. The biggest challenge for power systems is the recent power outages in the world. Analysis of the causes and consequences of blackouts is important because it affects human life as both social and economic. With deep analysis can be minimized the blackouts and its effects. Then, for other blackouts can perform the required arrangements. In this research, in addition to the causes of worldwide power blackouts and Turkey's blackouts, influence areas and about the precautions to be taken were informed. In addition, electrical blackout analyzes were carried out via a sample power system.
\end{abstract}

Keywords: Power System Analysis, Power Blackout, Power System Reliability, Smart Grid.

\section{Giriş}

Günümüzde kullanılan güç sistemleri, genellikle büyük güçlü merkezi üretimli sistemlerdir. $\mathrm{Bu}$ sistemlerde üretimin önemli bir rol oynamasından dolayı elektrik üretim santralleri petrol, kömür ve doğalgaz gibi geleneksel enerji kaynaklarının yoğun olduğu bölgelerde kurulmaktadır. Bu santrallerde

*Sorumlu yazar: ozge4492@ @mail.com
Geliş Tarihi: 04.01.2019, Kabul Tarihi: 07.05.2019 
üretilen enerji, gerilim düşümleri ve kayıplar dikkate alınarak yüksek gerilim seviyelerinde kısa veya uzun iletim hatları üzerinden tüketim bölgelerine taşınmaktadır.

Dünyadaki artan nüfus ve teknolojideki gelişmelerle birlikte enerjiye olan ihtiyaçta sürekli bir artış gözlemlenmektedir. Artan enerji talebinin karşılanması esnasında mevcut sistemler ve üretim yapılarından kaynaklı bazı zorluklarla karşılaşılmaktadır. Yaşanılan zorluklara karşı çözüm olarak öne sürülen rüzgâr ve güneş enerjisi gibi yenilenebilir enerji kaynaklarının değişkenlikleri ve aralıklı doğaları nedeniyle yeni zorluklarla karşılaşılması olasıdır [1,2]. Hali hazırda var olan karmaşık yapısının yanı sıra yeni zorlukların da ortaya çıkmasıyla birlikte güç sistemlerinde elektrik kesintilerinin yaşanması kaçınılmazdır. Genel olarak küçük ölçekli kesintiler, enerji arzının İsveç’te 1 dakikadan, İngiltere'de 3 dakikadan, Amerika' da 5 dakikadan fazla olması durumu şeklinde ifade edilmekle birlikte kesin bir tanımı olmayıp ülkeden ülkeye farklılık göstermektedir [3]. Büyük ölçekli elektrik kesintileri ise bir bölgedeki elektrik üretimi, iletimi ve dağıtım sistemlerinin bir kısmının ya da tamamının kısa veya uzun süreli olarak kayba uğraması şeklinde ifade edilmektedir [4].

Güç sistemleri genel olarak küçük ölçekli kesintilerle başa çıkabilecek şekilde tasarlandığ 1 için sistem mühendislerinin asıl odak noktası büyük ölçekli elektrik kesintileridir. Elektrik enerjisinin sürekliliği ve güvenilirliği oldukça önemli olduğundan sistem tasarımları yapılırken oluşabilecek kesinti risklerini en aza indirgeyecek şekilde gerekli önlemler alınmasına rağmen çeşitli nedenlerden dolayı büyük çaplı elektrik kesintilerinin önüne geçilememektedir. Geçmişte olduğu gibi günümüzde de gelişen teknolojiye ve koruma sistemlerine rağmen bu tarz büyük ölçekli kesintiler dünya genelinde de tecrübe edilmektedir. Özellikle 2000'li yılların başlangıcından itibaren elektrik kesintilerinde önceki dönemlere göre daha fazla bir artış gözlemlenmiştir. Bu artışın yaşanmasında güç sistemlerinin artan enerji talebinin karşılanmak istenmesi etkili olmuştur. Mevcut sisteme yeni üretim, iletim ve dağıtım birimlerinin eklenmesi enerji sürekliliği açısından büyük katkı sağlarken güvenilirlik açısından bir bütün olarak hareket etmek zorunda olan enterkonnekte sistemleri daha kolay etkileyebilmektir. Diğer bir ifadeyle sistemin düşük güçlü ve en az riske sahip noktasında dahi herhangi bir olay veya arıza meydana gelse bile zincirleme bir reaksiyon göstererek büyük ölçekli kesintilere neden olabilir. Şekil 1'de ise bu tarz elektrik kesintilerinin meydana gelme mekanizması verilmiştir. Bu yüzden son dönemlerde artan kesintilerin sosyal hayat, ekonomi ve sistem üzerindeki etkilerini en aza indirgemek için yaşanılan elektrik kesintilerinin iyi bir şekilde analiz edilmesi ve en uygun gelecek planlamasının yapılması bakımdan büyük önem taşımaktadır.

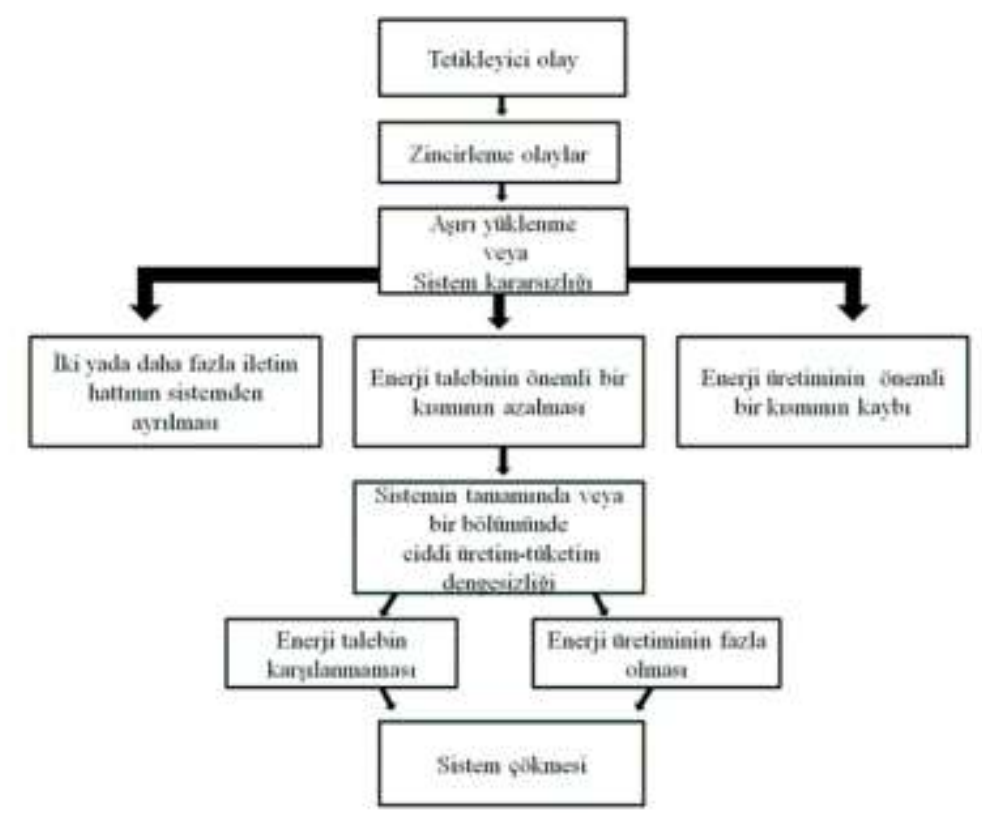

Şekil 1. Genel elektrik kesintilerinin meydana gelme mekanizması

Çalışma sırasıyla şu bölümlerden oluşmaktadır; ikinci bölümde elektrik kesintilerinin oluşmasında etkili olan olası nedenler açıklanmıştır. Üçüncü bölümde dünyada yaşanan elektrik 
kesintileri, etkilenen kişi sayısı, kesinti nedenleri, restorasyon süreci, kesinti öncesi ile sonrasında sosyal yaşam ve ekonomi üzerindeki gözlemlenen etkiler vb. kriterler göz önünde bulundurularak analiz edilmiştir. Dördüncü bölümde Türkiye'de meydana gelen elektrik kesintileri değerlendirilmiştir. Beşinci bölümde dünyada ve Türkiye'de yaşanan kesintilerden hareketle IEEE 39 baralı güç sistemi üzerinden çeşitli senaryolar oluşturularak benzetim çalışması yapılmıştır. Altıncı bölümde elektrik kesinti analizlerine dair gelişmeler ifade edilmiştir. Son bölümde ise kesintilerin önüne geçebilmek veya etkisini en aza indirmek için atılması gereken adımlar hakkında önerilerde bulunulmuştur.

\section{Elektrik Kesintilerine Genel Bakış}

Güç sistemlerinin sürekli enerji arzının sağlayabilmesi için frekans ve gerilim değerlerini yönetmeliklerde belirtilen aralıkta tutulması gerekir. Bununla birlikte sistemde oluşabilecek küçük bozulmalara karşı kendini yenileyebilmesi beklenir. Aksi takdirde küçük bozulmaları etkisiz hale getirilememesi durumlarında, sistemde beklenmedik büyük kayıplara neden olan elektrik kesintileriyle de karşılaşılabilir.

Büyük ve karmaşık sistemlerde, büyük ölçekli elektrik kesintisi risklerinin kaçınılamaz bir şekilde her zaman var olduğu gözlemlenmiştir. Bu risklere karşı alınabilecek önlemler ve dayanıklı bir güç sistemi tasarımları için tecrübe edilen kesintilerin iyi analiz edilmesi gerekir. İyi bir kesinti analizi yapabilmek için kesinti öncesi şartların, kesintiye sebep olabilecek nedenlerin, arıza sonrası sistemde gerçekleşen olayların, arızanın ne kadar süre devam ettiğinin, sistemin toparlanma aşamalarının ve arızanın sistem-sosyal hayat-ekonomi üzerindeki etkileri bir bütün olarak değerlendirmelidir.

Meydana gelen elektrik kesintilerinin, kesinti öncesi şartları incelendiğinde iki durum göze çarpmaktadır. Bunlardan ilki mevsim normallerinin üstündeki aşırı sıcaklıklar ve bu sıcaklıkların getirisi olarak aşırı yüklü şekilde sistemlerin çalışmasını sürdürmesi durumudur. Diğeri ise planlı ya da planlanmamış üretim, iletim veya kapasitör banklarının çok sayıda servis dışı olması durumudur [5].

Kesinti analizlerinin en önemli kriteri ise kesintiye sebep olacak tetikleyici olayın bilinmesidir. Elektrik kesintilerinin ortaya çıkmasında, mevsim değiş̧iminden teknik arızaya dahası terör saldırılarına kadar birçok faktör etkili olmaktadır. Bu faktörler genel olarak 3 gruba ayrılabiliriz [4, 6, 7]:

a) Dış ortamdan kaynaklı nedenler: Elektrik kesintileri genel olarak deprem, kasırga, heyelan, tsunami gibi doğal afetlerden veya şiddetli rüzgâr, yoğun yağmur yağışı, yıldırım düşmesi, kar firtınası, tropikal firtınalar, aşırı sıcaklık gibi yoğun hava koşullarından kaynaklanabilir. Bu nedenlere ek olarak göz ardı edilse de ciddiye alınması gereken nedenlerden bir tanesi de bitki örtüsünün elektrik sistemleriyle temasa neden olabilecek yakınlığıdır.

b) Teknik yapıdan kaynaklı nedenler: Elektrik kesintilerinin bazıları, şebeke yapısı ile şebeke elemanlarının yetersiz ve eskimiş olmasından olabileceği gibi elemanların yapısından kaynaklı yanlış çalışması sonucunda da oluşmaktadır.

c) Yönetimsel aksaklıklardan kaynaklı nedenler: Yaşanılan kesintilerin bazı ise arz-talep dengesizliğine sebep olacak şekilde aşırı üretim yapılması, hatalı yük tahminlerinin yapılması, alt yapı yatırımı ve bakım eksikliği, verimsiz ve dağınık elektrik planlamaları, iletişim ve koordinasyon eksikliği, (N-1) güvenlik kriterinin ihlal edilmesi, çalışanların bilgisiz ve tecrübesiz olmasından meydana gelmektedir.

Dünya genelinden yaşanılan elektrik kesintiler incelendiğinde kesintilerin, diğerlerine kıyasla daha çok dış ortamdan kaynaklı nedenlerden dolayı meydana geldiği gözlemlenmektedir. Özellikle yaz (Temmuz-Ağustos) ile kış (Kasım-Şubat) aylarının yaşandığı mevsimsel dönemlerde elektrik kesintilerinin en sık yaşandığı dönemlerdir. Bahsedilen mevsimsel dönemlerdeki aşırı ısınma ve soğuma, enerji talebinin normalin üzerine çıkmasına ve ekipman arızalarının yaşanmasına neden olabilir. Bu noktadan hareketle tetikleyici olayı oluşturan nedenler faklı olmasına karşın zincirleme reaksiyonlar esnasında diğer nedenlerde kesintinin şiddetini arttırabildiği görülmüştür.

Tetikleyici olayın, başlangıç noktasından sistemin önemli bir kısmına ya da tamamına etki etmesi sürecinde sistem bünyesinde;

- Üretim-tüketim dengesizliği,

- Kısa devreye bağlı dinamik kararlılık kaybı,

- Aşırı yüklenmiş hatların açılmasına bağlı açı kararlılı̆̆ı kaybı, 
- İletken sarkmaları nedeniyle meydana gelen arıza sonucu çoklu hat açması,

- Düşük gerilim kaynaklı koruma işlemlerinin çoklu hat açması,

- Gerilim düşmesi veya çoklu hat açılmasından dolayı ani yük eksikliği,

- Gerilim ve frekans kararlılığının sınır noktalarını aşmaları

gibi olaylar meydana gelebilir [8]. İfade edilen olaylardan en az birinin yaşanması halinde sistem üzerinde zincirleme reaksiyon etkisi göstererek felaket olarak nitelendirilebilecek elektrik kesintisine sebep olabilir.

Elektrik kesintileri açısından dikkat çekici bir nokta ise kesintisinin gerçekleştiği bölgedir. Yapılan çalışmalara göre büyük ölçekli kesintilerin, nüfusun ve sanayinin yoğun olduğu Kuzey Amerika kıtasında gerçekleştiği görülmüştür. Bunu Asya ve Avrupa kıtaları takip etmektedir [9]. Kesinti sıklığı bakımından incelediğinde ise Asya kıtasının özellikle güney kısımlarının ilk sırada yer aldığı görülmektedir.

Kuzey Amerika'da yaşanan kesintilerin nerdeyse tamamının oluşumunda kasırga ve rüzgâr fırtınaları etkilidir. Öte yandan Asya ve Avrupa'da oluşan kesintilerde ise Kuzey Amerika'daki gibi net bir ifade söylemekten ziyade faktörler eşit dağılmış denilebilir.

Tablo 1. Elektrik kesinti kronolojisi [7]

\begin{tabular}{|c|c|c|c|}
\hline Tarih & Elektrik Kesintisi & $\begin{array}{c}\text { Etkilenen Ínsan } \\
\text { Saynsı }\end{array}$ & Kaybedilen Yük \\
\hline 31 Mart 2015 & Turkiye & 70.000 .000 & 32.200 \\
\hline 30-31 Temmuz 2012 & Hindistan & 670.000 .000 & 48.000 \\
\hline 8 Eylül 2011 & $\begin{array}{c}\text { Arizona ve Baja } \\
\text { Kaliforniya }\end{array}$ & 8.100 .000 & 7.835 \\
\hline 4 Şubat 2011 & Brezilya & 40.000 .000 & 8.884 \\
\hline 26 Subat 2008 & Florida & 3.000 .000 & 3.650 \\
\hline 26 Nisan 2007 & Kolombiya & 41.160 .000 & 6.644 \\
\hline 4 Kasım 2006 & UCTE & 45.000 .000 & 14.500 \\
\hline 24 Eylul 2006 & Pakistan & 160.000 .000 & 11.160 \\
\hline 12 Temmuz 2004 & Atina & 5.000 .000 & 4.500 \\
\hline 28 Eylül 2003 & ttalya & 57.000 .000 & 24,000 \\
\hline 23 Eylü 2003 & Danimarka ve Isvec & 4.000 .000 & 6.550 \\
\hline 28 Ağustos 2003 & Londra & 410.000 & 724 \\
\hline 14 Ağustos 2003 & Kuzey Amerika & 50.000 .000 & 61.800 \\
\hline 31 Mart 2003 & İan & 22.000 .000 & 7.063 \\
\hline 18 Mart 1978 & Tayland & 40.000 .000 & 1.336 \\
\hline 9 Kasım 1965 & $\mathrm{ABD}$ & 30.000 .000 & 20.000 \\
\hline
\end{tabular}

Elektrik kesintilerinin ciddiyeti açısından en önemli kriterler ise etkilenen insan sayısı, kaybedilen yük ve kesintisi süresidir. Araştırmacılar tarafından yapılan çalışmalar ve ilgili kurumların sunmuş olduğu raporlar doğrultusunda bahsi geçen üç kriter bağlı olarak yapılan elektrik kesinti kronolojisi Tablo1'de verilmiştir [6, 7, 10-13]. Bu sınıflandırmaya göre hem etkilenen insan sayısı hem kaybedilen yük hem de kesintisi süresi bakımından bugüne kadar yaşanan dünyadaki en büyük kesinti Hindistan'da olduğu görülmektedir. Bu ülkeyi sırasıyla Bangladeş, Pakistan, Java-Bali, Brezilya, Kuzey Amerika, Türkiye ve İtalya' da yaşanan kesintiler takip etmektedir.

Bugüne kadar modern güç sistemleri üzerinde tecrübe edilen elektrik kesintilerinin farklı nedenler sonucu meydana gelmesine rağmen belirgin olarak etkiledikleri alanın geniş olması, ekonomik kayıpların çok fazla olması ve sosyal hayatın durma noktasına gelmesi bakımından neredeyse benzerlik gösterdiği görülmektedir. Özellikle toplum yapısındaki ve teknolojideki gelişmeler beraberinde elektriğe olan bağımlılı̆g 1 da arttırdığı için herhangi bir elektrik kesintisinde büyük kayıplara neden olabiliyor. Durumun böyle olmasında, sosyal ve ekonomik düzen istikrarının, elektrik enerjisi güvenilirliği ile doğrudan bağlantılı olması etkilidir. Herhangi bir büyük ölçekli kesinti meydana 
geldiğinde üretimin durması, üretim ünitelerindeki ürünlerin hasar görmesi, satışların ve hizmetlerin gerçekleştirilememesi, bazı gıda ürünlerin bozularak kullanılamaz hale gelmesi ekonomiyi doğrudan etkilerken vergi gelirlerinin kaybedilmesi, yağmalama olaylarının olması, sigorta oranlarında keskin artışların olması, fazla mesai ödemelerinin olması ise ekonomiyi dolaylı olarak etkilemektedir [14]. Müşteri kesinti maliyetlerini etkileyen faktörlere odaklanan bir araştırmaya göre dolaylı etkilerin ekonomi üzerinde doğrudan olanlara kıyasla çok daha baskın olabileceğini ifade etmiştir [15]. Bunlara ek olarak kesintiler, borsa ile finansal işlem sistemlerinin çalışmasını etkileyebilir ve insanların paniğe kapılması sonucu finansal istikrarsızlığa neden olabilir.

Kesintilerin sosyal düzen üzerindeki etkileri de göz ardı edilmeyecek noktadadır. Sosyal düzeni;

- Trafik sinyalizasyonundaki bozulmadan kaynaklı trafik tıkanıklığ ;

- Hizlı tren, metro ve tramvay seferlerinin durması ve yolcuların mahsur kalmas1,

- Uçakların acil iniş yapması ve yapılması planlanan uçak seferlerinin iptal edilmesi,

- Sabit ile mobil telefon hatlarının ve internetin servis dışı kalması sonucu iletişimde aksamaların yaşanması,

- Kesinti anında madende insanların mahsur kalması veya gerekli yardımın yapılmaması sonucu ölmesi,

- Rafineri veya fabrikalarda kazaların yaşanması,

- Çatışmaların ve kargaşanın baş göstermesi,

gibi durumlar etkilemektedir [6]. Elektrik kesintilerinin yaratacağı en büyük sıkıntılar ise insan hayatını doğrudan etkilediği için hastane ve tıbbi tesislerin çalışmasında yaşanabilecek aksaklıklardır.

\section{Dünyada Meydana Gelen Elektrik Kesintileri}

Bu bölümde kayıtlara geçen ilk elektrik kesintisinden günümüze kadar meydana gelen büyük elektrik kesintileri, yayınlanan raporlar ve çalışmalar doğrultusunda yukarıda bahsedilen kriterler göz önünde bulundurularak analiz edilmiştir.

Resmi kayttlara göre bildirilen ilk kitlesel elektrik kesintisi 9 Kasım 1965 tarihinde ABD'de yaşand. İlk olarak Sir Adam Beck Hidroelektrik santralinin Ontario bölgesine bağlanan 5 adet 230 kV'luk iletim hatlarından birine ait olan kesici rölesinin geçici aşırı akım anında açmasını takiben normal şekilde çalışan hatların açılması olayı tetiklemiştir. Bu olayı takiben diğer hatlarında aşırı yüklenmeden dolayı açtığı gözlemlenmiştir. Açma olayları, zincirleme bir reaksiyona dönüşerek 12 dakika içerisinde ABD'deki 30 milyon insanın elektriksiz kalmasına neden olmuştur. Amerika'daki elektrik endüstrisini yaşadığı en büyük tehlike olarak kayda geçen kesinti, bazı bölgelerde 13 saat kadar sürmüştür. 20.000 MW'lık bir yük kesintisi olmuştur. Olay esnasında tren ve uçuş seferleri durmuş, 855 hastane enerjisiz kalmıştır. Toplamda 100 milyon dolarlık ekonomik kayıp olduğu tahmin edilmektedir [16].

18 Mart 1978 tarihinde tek bir jeneratör arızasının başlattı̆̆ birbiri ardına gelişen olaylar sonucu Tayland elektrik sistemi çökmüştür. 9 saat süren kesinti boyunca 1.336 MW'lık yük enerjisiz kalması sonucu 40 milyon insan etkilenmiştir [3].

1978 ile 2001 arasında meydana gelen kesintiler diğer kesintilerle kiyaslandığında daha az etkiliye sahiptir. 2 Ocak 2001 tarihine gelindiğinde ise Hindistan'ın Uttar Pradesh kentindeki trafo arızası sonucu başlayan elektrik kesintisi ülke geneline yayılmıştır. Kesinti sonucunda 230 milyon kişiye 16 saat enerji verilememiştir. Ekonomik kaybın 110 milyon dolar olduğu tahmin edilen kesinti sonrasında trafik sinyalizasyonun ve mobil iletişim ciddi sıkıntılar yaşanmışıır [4].

28 Eylül 2003 tarihinde İtalya'da meydana gelen kesintinin oluşumunda aşırı yüklü hatları 1sınmasıyla iletkenlerin sarkması etkili olmuştur. Sarkma sonucu iletkenlerden ağaç dalları üzerine atlamalar yaşanmıştır. Bu durum kısa devre arıza zinciri başlatarak UCTE (Elektrik İletim Koordinasyon Birliği) tarafından belirlenen kararlılık sınırlarını aşmasına neden olmuştur. Bu durum ise başta İsviçre olmak üzere Fransa, Avusturya ve Slovenya ile İtalya'nın şebeke bağlantılarını koparmıştır. Aralarında 4 kişinin de öldü yaklaşık olarak 57 milyon insanın etkilendiği elektrik kesintisi süresince 24.000 MW'lık yük kaybedilmiştir. 5 ila 9 saat elektrik verilemeyen sistem 13,5 saat sonra restorasyonunu tamamlamıştır [10, 17]. 
14-15 Ağustos 2003 tarihinde $\mathrm{ABD}$ ve Kanada'da toplam gücün \%11'ine denk gelen 61.800MW'lık yükü besleyen sistem çökmüştür. Yaz ayları olması nedeniyle aşırı klima kullanımına bağlı olarak yetersiz reaktif güç kaynaklı gerilim kararsızlığının oluşması ve ağaç dalları kesiminin uygun olmamas1 olayın temel nedenleridir. ABD'de 16 ila 72 saat, Kanada ise 192 saate kadar enerji temin edilememiştir. 50 milyon insanın etkilendiği kesintinin ABD için maliyeti 10 milyon dolarken Kanada için 1 milyon Kanada dolarıdır [5, 7, 12].

18 Ağustos 2005 tarihinde Java, Bali ve Endonezya'yı kapsayan 8 adet elektrik üretim tesisinin arızalanması sonucu sistem çökmeleri meydana gelmiştir. Teknik arızalardan kaynaklanan arıza sonucu 100 milyon insan 7 saat boyunca enerji verilememiştir [4].

4 Kasım 2006'da Almanya, Fransa İtalya ve İspanya'da aşırı yüklenme ve koordinasyon hataları sonucunda geniş çaplı elektrik kesintisi yaşanmıştır. 45 milyon insanın etkilendiği kesintide 14.500 MW'lık yük beslenememiștir. 2 saatlik kısa kesinti ekonomik zararı 139 milyon dolardır [11].

10-11 Kasım 2009'da Brezilya ve Paraguay'1 kapsayan kesintinin oluşumunda şiddetli yağmur ve rüzgâr nedeniyle meydana gelen kısa devre arızaları etkili olmuştur. Toplamda 87 milyon insanın etkilendiği kesintide güvenlik sorunları yaşanmıştır. Ayrıca sabit telefon hattı da çökmüştür [4].

30-31 Temmuz 2012'de Hindistan'da 670 milyon insanın enerjisiz kalmasına neden olan elektrik kesintisi dünya tarihinin en büyük kesintisi olarak ifade edilmektedir. Kesintiye, yüksek sicaklık nedeniyle 132, 220 ve $400 \mathrm{kV}$ 'luk hatların aşırı yüklenmesi sonucu başlayan hat açmaları ile yüksek frekanstan dolayı jeneratörler servis dışı kalması neden olmuştur. Birkaç elektriksel bölgeye ayrılarak ayakta kalmaya çalışan sistem kısa bir süre sonra çökmüş ve 48.000MW'lık yük kaybedilmiştir. 2 ila 8 saat süren kesintilerde sosyal anlamda büyük bir felaket yaşanmıştır [18].

1 Kasım 2014 tarihinde Bangladeş’te ülke çapında gün boyu etkili olan elektrik kesintisine, bazı jeneratörlerin bakımda olması ve Hindistan'dan enerji (445 MW) ithal edilememesi sonucu mevcut gücün beslenememesinden dolayı güç sistemi çökmüsstür. Olay süresince düşük frekansta planlanandan düşük yük atılması durumu daha da kötüleştirmiştir. Kesintiden toplamda 150 milyon insan etkilenmiştir [5].

23 Aralık 2015 tarihinde Ukrayna'da senkronize ve koordineli bir şekilde üç bölgesel dağıtım şirketine siber saldırı düzenlenmiştir. Bu siber saldırı sonucunda elektrik kesintisi meydana gelmiştir. Yaklaşık olarak 225.000 insanın etkilendiği bu olay, dünyada siber saldırı nedeniyle meydana gelen ilk kesinti olarak kayıtlara geçmiştir. Siber saldırılar, geleneksel hatalar ve fiziksel saldırılardan farklıdır. Bu tip saldırılar, güvenlik açıklıklardan faydalanarak güç sistemi bilgi altyapısına ulaşılması ve istenilen müdahalelerin yapılmasına olanak sağlamaktadır $[4,19]$.

28 Eylül 2016 tarihinde şiddetli firtına nedeniyle Güney Avusturalya sistemi çökmüştür. 1.7 milyon kişinin elektriksiz kaldığı elektrik kesintisinde, bir dizi şebeke hatası meydana gelmesine rağmen sistem kararlı bir şekilde çalışmasını sürdürmüştür. Mevcut hataların temizlenememesinin yansıra enerji talebinin \%17,6's1 geleneksel kaynaklardan, \%50'si rüzgâr ve güneş enerjisi gibi yenilebilir enerji kaynaklarından kalan kısım ise ara bağlantılardan karşılanmasından dolayı kısa sürede bazı üretim birimleri devre dışı kalarak açısal kararsızlığın oluşmasına neden olmuştur. Yaşanan bu kararsızlığın tüm sisteme yansımasıyla gerçekleşen sistem çökmesi, yüksek yenilenebilir enerji entegrasyonu nedeniyle bilinen ilk sistem çökmesi olarak kayıtlara geçmiştir. Kesinti sonucu 1.826 MW yük kaybı ve 367 milyon dolarlık (Avustralya doları) ekonomik kayıp söz konusudur [20].

12 Nisan 2018'de işçilerin bitki örtüsü temizlemesi esnasında bir ağacın Cayey kasabası yakınlarındaki büyük bir elektrik hattına düşmesiyle Porto Riko'daki 870.000 kullanıcı elektriksiz kalmıştır. Bu olaydan bir hafta sonra 18 Nisan'da, 2017 yılında meydana gelen Maria kasırgasının iletim hattındaki hasarını tamir eden bir ekskavatör iki büyük enerji santralini birbirine bağlayan bir hatta çarpmasıyla Porto Riko genelinde güç kesintisi yaşanmıştır [21].

\section{Türkiye'de Meydana Gelen Elektrik Kesintileri}

17 Ağustos 1999'da Türkiye'de meydana gelen elektrik kesintisi, ülke kayıtlarına geçen ilk büyük ölçekli kesintidir. Bu kesintinin oluşumundaki en büyük etken 17 Ağustos depremidir. Deprem nedeniyle özellikle elektrik iletim hatlarının zarar görmesi sonucu 62 milyon insana enerji verilememiştir. Depremin etkilediği Marmara Bölgesi, gerek üretim-tüketim kapasitesi gerekse Türkiye ekonomisi açısından önemli bir konuma sahip olması bakımdan kritiktir. Öte yandan çok fazla üretim 
ve maddi kayıp yaşanmasına rağmen 18 Ağustos akşamına kadar bölgesel restorasyonlar sonucu sistem ayağa kaldırılmıştır [22, 23].

14 Ocak 2012'de yaşanan elektrik kesintisi, soğuk hava koşullarını nedeniyle Bursa Doğalgaz Kombine Çevrim Santralindeki teknik bir arıza sonucu oluşmuştur. Özellikle İstanbul, Sakarya, Kocaeli, Tekirdağ, Kırklareli ve Edirne'de etkili olan kesinti süresince 20 milyon insan elektriksiz kalmıştır. Yaklaşık olarak 5 saat süren çalışmalar sonucu güç sistemi sorunsuz bir şekilde çalışmaya başlamıştır [23].

31 Mart 2015 tarihinde Türkiye Elektrik Sistemi'nde, 400 kV iletim hattının aşırı yüklenerek servis dışı kalmasıyla ve ENTSO-E Avrupa Kıtası sisteminden ayrılması sonucu sistem çökmesi yaşanmıştır. Bu durum, Türkiye Elektrik Sistemi'nin bugüne kadar yaşamış olduğu en büyük elektrik kesintisidir. Ayrıca Avrupa'da son on yılda meydana gelen üçüncü büyük kesinti olarak kabul edilmektedir. Kesinti öncesinde 4 adet $400 \mathrm{kV}$ iletim hatları ile tüm seri kapasitör banklarının bakım ve arıza nedeniyle servis dışı durumdaydı. Bunun yanı sıra ülkenin doğusundaki hidroelektrik enerji üretim fazlalığından kaynaklı doğu batı yönlü enerji transferinin hatlarda aşırı yüklenmeye sebep olması güç sistemini zayıflatmıştır. Bu koşullar altında sistem çökmesi, ilk olay olarak kayda geçen OsmancaKurşunlu enerji iletim hattının açısal kararsızlık nedeniyle servis dışı kalmasından sonraki 12 saniyede meydana gelmiştir. Kesinti sırasında düşük frekansta yük atma eyleminin planlandığ gibi olmaması elektrik sistemini, önce doğu ve batı alt sistem olarak ikiye ayrılmıştır. Şekil 2'de doğu alt sisteminde üretim fazlalığına bağlı yüksek frekans, batı alt sisteminde ise talep fazlalığına bağlı düşük frekans görülmektedir. Yaşanılan sistem bölünmesinden çok kısa süre sonra da elektrik sistemi çökmüştür. 70 milyon insan 7-8 saat boyunca elektriksiz kalmıştır [13]. Özellikle İstanbul ve Ankara gibi büyükşehirler, yüksek nüfus ve gelişmiş sanayi yapısı nedeniyle kesintiden daha çok etkilenmiştir. Metro ve tramvay seferleri durmuş, tekstil ve otomotiv sanayisinde büyük sorunlar yaşanmıştır. Gayri Safi Yurtiçi Hâsıla üzerinden yapılan hesaplamaya göre saatlik 100 milyon dolarlık ekonomik kayıp söz konusudur [3].

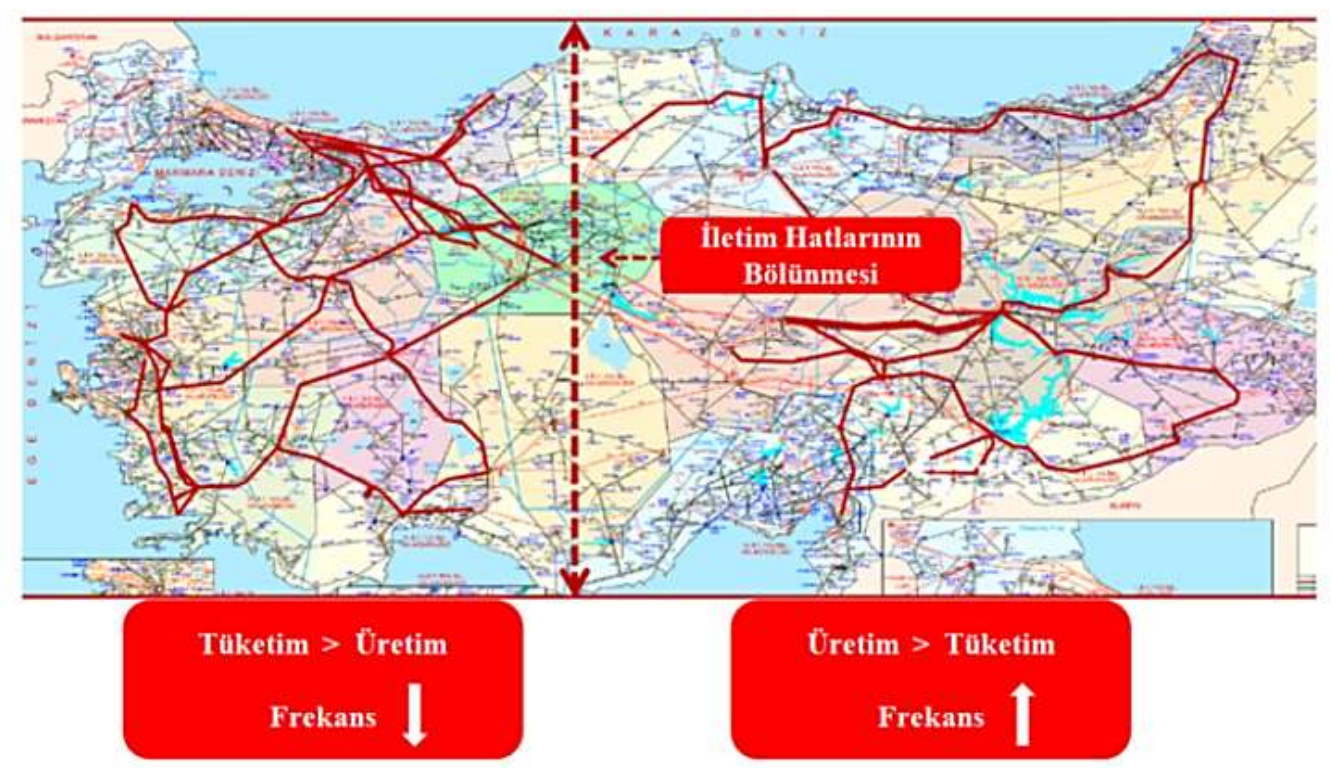

Şekil 2. Türkiye Elektrik Sistemi iletim hatlarının bölünmesi [24]

\section{Benzetim Çalışması}

Mevcut elektrik alt yapıs1, akıllı şebekelere geçiş sürecinde karmaşık iletişim ve kontrol sorunları ile enterkonnekte sistemlerde basamaklı arıza risklerinin artmasına neden olmaktadır. Arıza risklerin artması ise güvenlik açığı ve endişelerini de beraberinde getirmektedir. Öyle ki tek bir arıza ya da 
beklenmedik bir durum belirli koşullar altında elektrik şebekesinde bozucu ve öngörülemeyen rahatsızlıkların art arda gelerek sistemin çökmesine neden olabilir.

Yaşanılan tecrübeler gösteriyor ki elektrik şebekesinin kararlılığını arttırmak için kesintiye neden olan arızaların ardındaki mekanizmanın tam olarak anlaşılması giderek önemli bir konu haline gelmektedir. Bu noktadan hareketle bu bölümde basamaklı arızaların neden olduğu sistem çökmesini gözlemleyebilmek amaciyla New England olarak da bilinen ve New England iletim sisteminin $34 \mathrm{kV}$ beslemesini gösteren IEEE 39 baralı güç sistemi kullanılmıştır. Bu sistemin tercih edilmesinde senaryoların kolay oluşturulabilecek şebeke büyüklüğü ve sadeliğine sahip olmasının yanı sıra birçok araştırmada konu olması etkili olmuştur. 10 jeneratör, 46 iletim hattından oluşan 39 baralı güç sisteminin herhangi bir kesinti olmadan öncedeki güç akışı Şekil 3'de verilmiştir. Bu sistem üzerinde literatürdeki çalışmalar dikkate alınarak kesinti analizi yapabilmek için 3 senaryo oluşturulmuştur. Ayrıca yapılan analizler sırasında herhangi bir güç sistemi dengeleyicisi kullanılmamıştır.

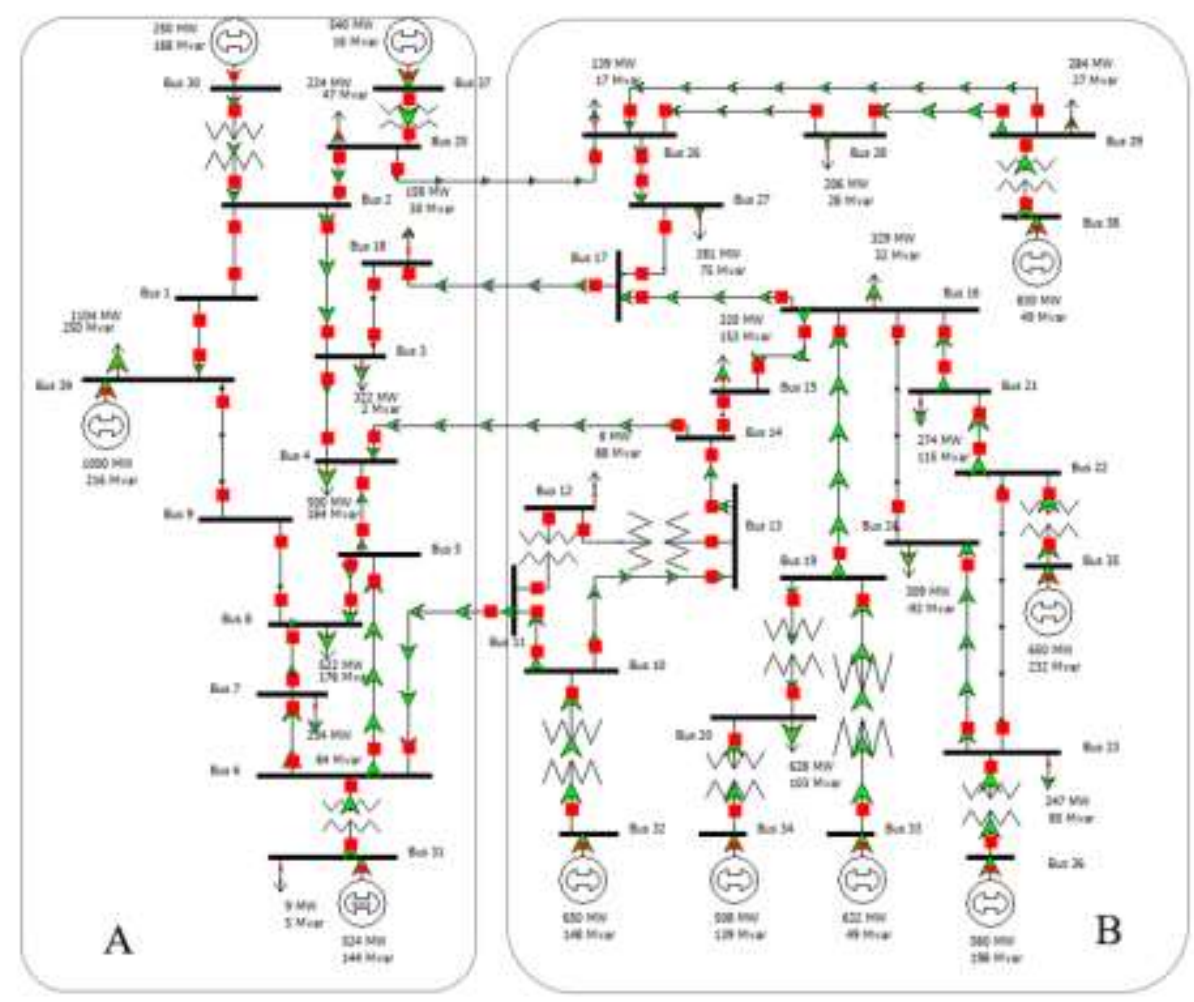

Şekil 3. 39 baralı güç sistemi

\subsection{Senaryo: Alt Adalara Ayrilma}

Bu senaryoda Türkiye elektrik sistemi çökmesinden hemen önceki doğu ve batı alt sistemine ayrıma olayında olduğu gibi 39 baralı güç sistemi de A ve B şeklinde iki alt adaya ayırılmıştır. Bu ayrılmanın olması için (25-26), (17-18), (4-14) ve (6-11) iletim hatlarında art arda açılacak şekilde hat açması arıza tanımlanmıştır. Birer saniye aralıklarla gerçekleşen açmalar esnasında ilk iki hattın açması sistem üzerinde gözle görülebilir bir değişlik oluşturmasa da taşıdıkları güç yoğunluğu nedeniyle açması planlanan son iki hatta aşırı yüklenme olmuştur. Bu aşırı güç yoğunluğunun oluşmasında $\mathrm{B}$ adasında A adasına kıyasla daha fazla üretim biriminin yer alması etkili olmuştur. 4 hattın açma arızası vererek servis dışı olması ve sistemdeki diğer hatların normalden daha fazla yüklenmesine rağmen simülatörde "blackout" uyarısı gözlemlenmemiştir. Bu sonucun aksine oluşturulan arızalarda sistem bağımsız çalışabilen adalara ayrılsa bile bağımsız çalışma yapısına bağlı olarak basamaklı arızalar adalarda da gözlemlenebilir. Tıpkı Türkiye sisteminin doğu ve batı alt adalarına ayrılmasına rağmen kısa sürede bu alt sistemlerde de arızaların gözlemlenmesi gibi. Her iki durumda da sistem çökmesi tehlikesi yüksek olasılığa sahiptir. Bu olasılığı gözlemleyebilmek amacıyla B adasında 38. Baraya bağlı jeneratörü servis 
dışı bırakacak bir arıza tanımladığımızda Şekil 4'te gösterildiği gibi simülatörde "blackout" uyarısı vermektedir. Diğer taraftan A adası için de 39. Baraya bağlı jeneratörü servis dışı bırakacak bir arıza tanımladığımızda aynı "blackout" uyarısı gözlemlenecektir. Alt sistemlerin bu uyarıyı vermesinde ait oldukları adaların büyük üretim birimlerinden olması etkili olmuştur.

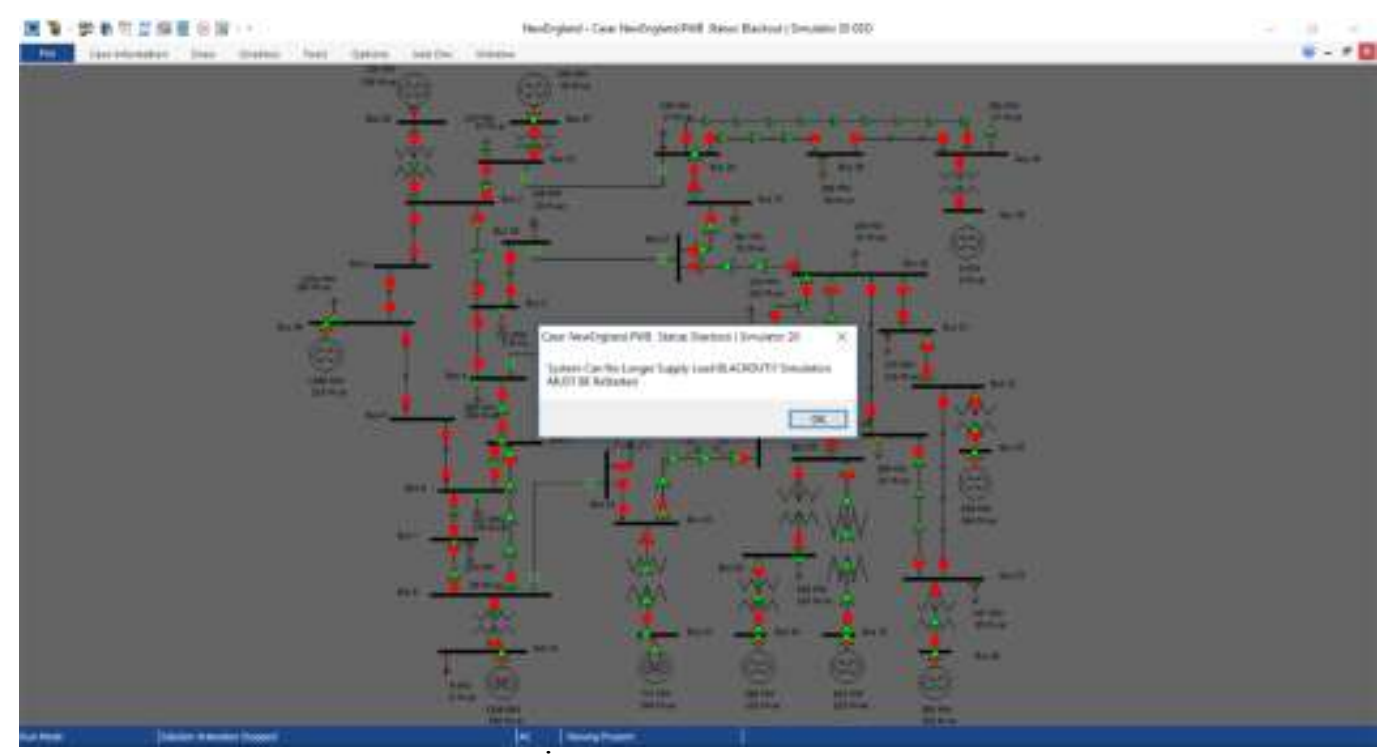

Şekil 4. İletim ve üretim kaybı durumu

\subsection{Senaryo: Așırı Yüklü Hatları Servis Dışı Kalması}

Kesintilerin anlaşılması, tahmini, azaltılması ve restorasyonu hakkında çeşitli simülasyon modelleri oluşturulurken gerçek sistem davranışlarına yaklaşmak için belirli varsayımlara odaklanılmalıdır. $\mathrm{Bu}$ varsayımlarda biri de teorik olarak bir baradaki acil durumun birden fazla hatta veya barada eş zamanlı arızalara neden olması durumudur. Bu varsayımdan hareketle birbiriyle bağlantılı iletim hatlarının servis dışı kalması durumunda sistemin vereceği tepki incelenmiştir. Bu analiz için 39 baralı güç sisteminde (5-6), (6-7), (3-4) ve (4-14) hatlarının çok kısa süreyle devre dışı kalacak şekilde hat açma arızası tanımlanmıştır. Bu hat açma arızaları sonucu Şekil 5'te görüldüğü gibi simülatörde "blackout" uyarısı vermiştir. Bu senaryo için seçilen hatların sistem genelinde en yüklü ve birbirileriyle bağlantılı olması bu uyarının verilmesinde etkili olmuştur. Sonuç olarak sistemin normal çalışma süresince aşırı yüklü hatların servis dışı kalması sistem çökme olasılığını arttıran bir durum olduğunu göstermektedir.

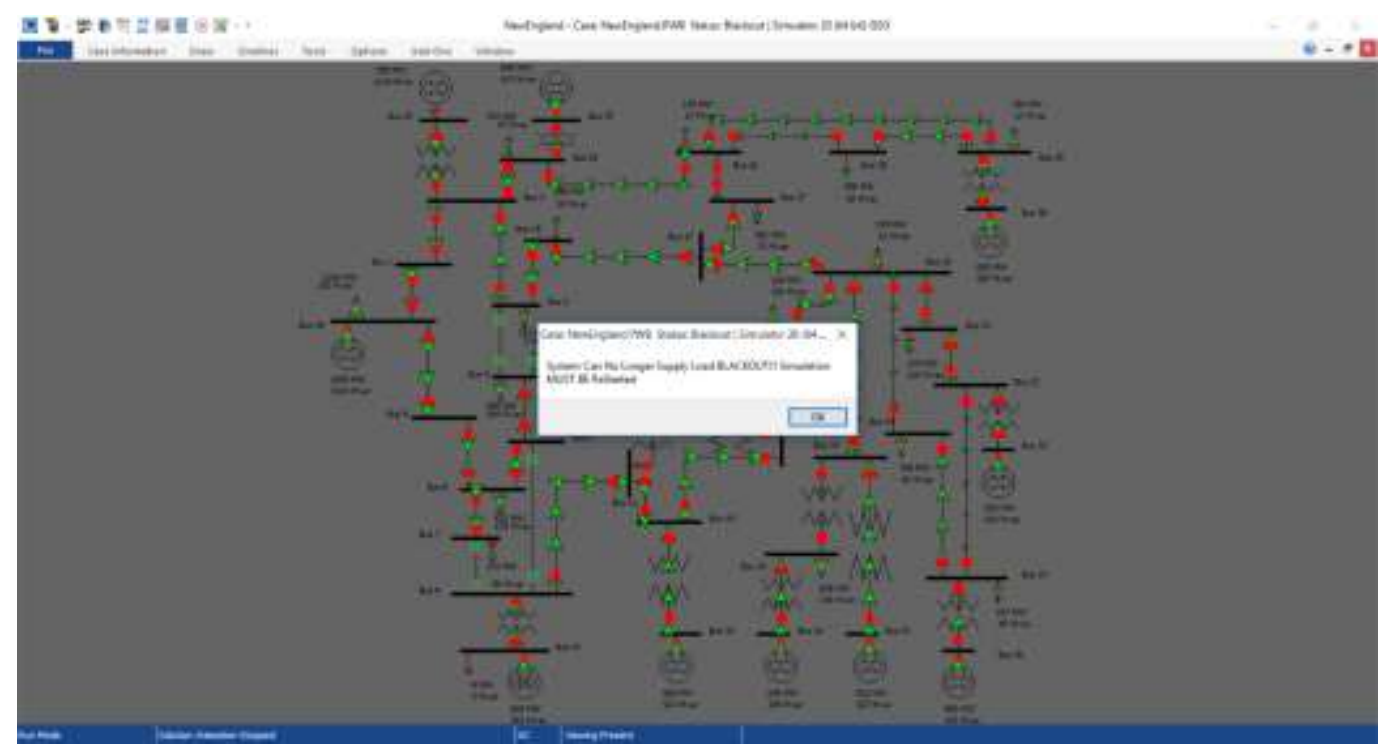

Şekil 5. (5-6), (6-7), (3-4) ve (4-14) hatların açması durumu 


\subsection{Senaryo: Üretim Kaybı}

$\mathrm{Bu}$ senaryoda ise yapılan çalışmalarda simülasyon modelleri oluşturulurken kullanılan bir diğer varsayım olarak kabul gören üretim kaybı durumu üzerinden kesinti analizi gerçekleştirilmiştir. 39 baralı güç sisteminde 39. Baraya bağlı jeneratör devre dışı olacak şekilde bir arıza tanımlanmıştır. Özellikle bu baraya bağlı jeneratörün seçilmesinde bugüne kadar yapılan birçok çalışmada büyük ölçekli kesinti olasılığının ve ölçeğinin, elektrik şebekesinin büyük güçteki üretim birimleriyle yüksek oranda ilişkili olduğu fark edilmiş olması etkili olmuştur. Tanımlanan bu arıza sonucu Şekil 6’te görüldüğü gibi simülatörde "blackout" uyarısı vermiştir. Bunun nedeni aynı barada bu jeneratörden beslenen ve sistemin en büyük güç talep eden yükünün enerjisiz kalması etkili olmuştur. Ayrıca elektriksel güç kaynaklarından mümkün olduğunca daha fazla faydalanmak için herhangi bir önlem alınmadan tasarım sınırlarına çok yakın çalıştırılması da bu tarz kesintilerin yaşanmasında etkili olur.

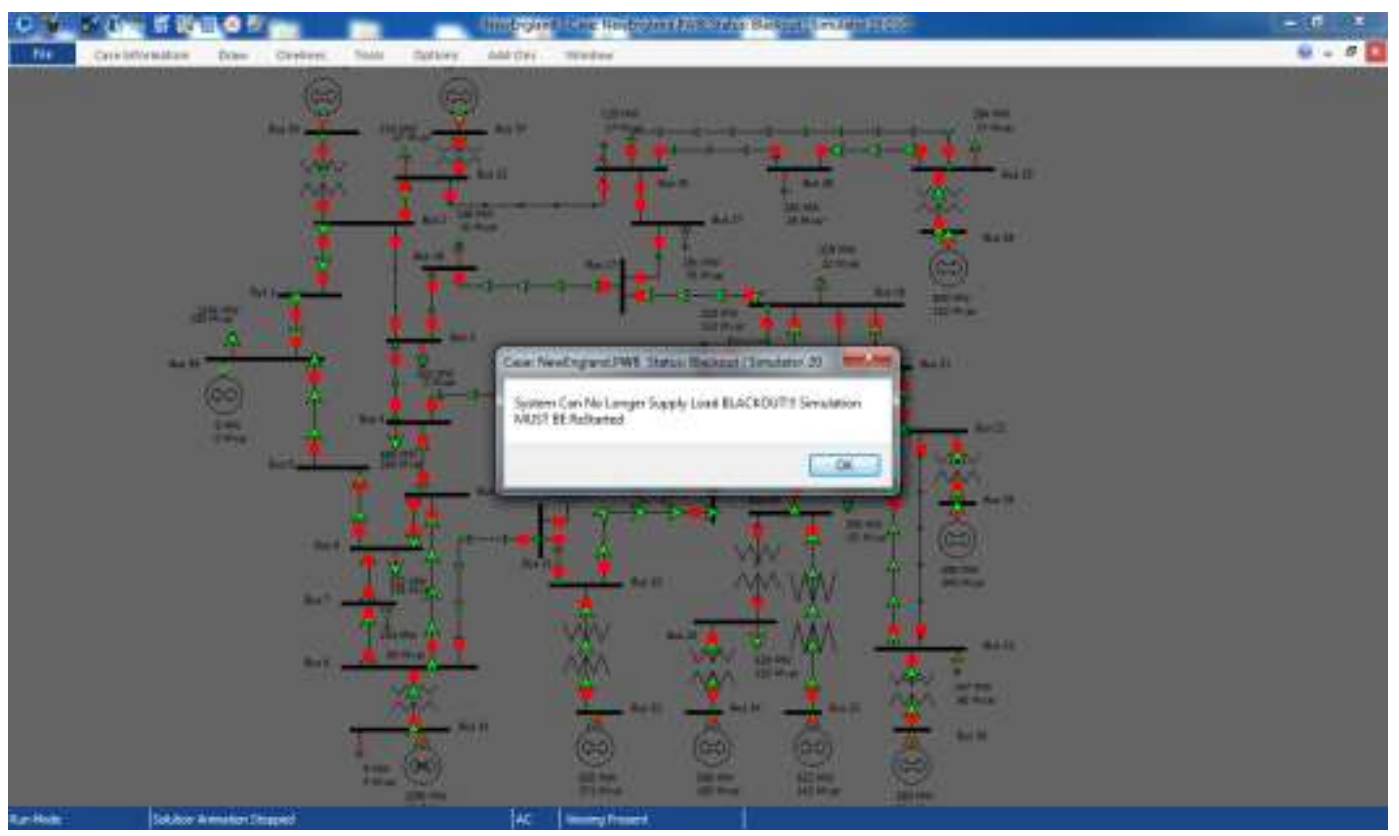

Şekil 6. 39.baradaki jeneratörün servis dışı kalması durumu

\section{Elektrik Kesintilerine Dair Güncel Gelişmeler}

İnsan yaşamının belirli standartlar içerisinde sürülebilmesi için gerekli olan sürekli ve kaliteli enerji teminini sekteye uğratması bakımından elektrik kesintileri büyük önem taşımaktadır. Meydana gelen kesintiler incelendiğinde temel kesinti nedenleri arasında ön plana çıkan aşırı yüklenme durumlarının önüne geçebilmek için etkili bir güç planlamasına ihtiyaç vardır. Etkili bir planlama ise gerçekçi kısa ve uzun dönem yük tahminleri ile yapılabilir. Özellikle yapay sinir ağları ve bulanık mantık modellerindeki gelişmeler etkili yük tahmini konusunda başarılı sonuçlar alınmasını sağlamıştır [25]. ANFIS (Adaptive Network Based Fuzzy Inference Systems) ve ARMA (Autoregressive Moving Average) modelleriyle yapılan çalışmalar sayesinde talep edilecek yükün önceden bilinmesi, buna bağlı olarak üretim, satın alma, bakım ve yatırım gibi kararların alınması bakımından avantaj sağlamaktadır [26]. Aşırı yüklenme durumları açısından bir diğer önemli nokta ise aşırı akım ve mesafe koruma rölelerinin çalışmasıdır. Gelecekteki karartma olaylarından kaçınmak ya da en azından ölçeklerini azaltmak amacıyla koruma rölelerinin çalışmasını iyileştirmek amaçlanmaktadır. Özellikle mikroişlemci kontrollü RTU (Remote Terminal Unit) gibi cihazların ve DLR (Dynamic Line Rating) gibi ileri yöntem algoritmalarının geliştirilmesi merkezi denetleme kontrol ve veri toplama sistemlerinin çalışmasına yardımcı olur [27]. Ayrıca bu gelişmelerin akıllı şebeke uygulamalarına geçiş sürecinde büyük katkı yapacağı düşünülmektedir. Elektrik kesintilerinde olayın meydana gelmesini önleyebilecek gelişmeler kadar kesinti sonrasındaki süreç de kritiktir. Elektrik kesintisi meydana geldikten sonra kontrollü bölünme 
yani ada moduna geçme, yük atma ve üretimin yeniden yapılandırılması kesintinin istenmeyen ekonomik ve sosyal etkilerini azaltmak için uygulanması gereken aşamalardır. Bu noktada elektriksel ada modu sınırlarının ve yük atma stratejilerinin uygulanabileceği program modelleri geliştirilmeli ve akıllı ölçüm sistemleri kullanılmalıdır. Sistem nerede, ne zaman ayrılabileceğine ve ne kadar yük atması gerektiğine de karar verecek duruma gelebilir [28]. Bu sayede akıllı şebekenin kullanıcılara vaat ettiği kendi kendini iyileştirme teknolojisi de sistem üzerinde uygulanmış olur [29, 31].

\section{Elektrik Kesintileri İçin Alınabilecek Önlemler}

Bugüne kadar yaşanmış elektrik kesintilerinden kazanılan tecrübeler büyük önem arz etmektedir. Bundan sonraki süreçte meydana gelebilecek benzer olayları önlemek için teknik, ekonomik, teknolojik ve insani açıdan bazı adımlar atılmalıdır. Güç sistemlerinin mevcut durumlarında daha güçlü, güvenilir ve kararlı bir yapıda olabilmesi için alınabilecek önlemler şunlardır:

- Güvenli bir şekilde güç sistemi planlanması, tasarımı ve bakımı yapılmalıdır.

- Programlanmış arıza ve bakım planlarının koordinasyonunun geliştirilerek hem maddi hem de zaman açısından tasarruf yapılmalıdır.

- Doğal afetlerden ve yoğun hava koşullarından kaynaklı kesintileri için tehlike uyarı tahmin sistemleri ile acil durum müdahale sistemleri kurulmalıdır.

- Üretim merkezleri veya iletim hatlarındaki herhangi bir arızaya rağmen sistemin (N-1) kriterine göre çalışmaya devam ettirilmelidir.

- Elektrik işletmelerindeki küreselleşmenin bir sonucu olarak şebeke güvenirliği açısından uluslararası bağlantılar yapılmalıdır.

- Büyük üretim merkezlerine ve uzun iletim hatlarına olan bağımlılığı azaltmaya gidilmelidir.

- Daha temiz ve esnek olma özelliğine sahip yenilenebilir enerji kaynaklarının dağıtık üretim şeklinde sistem içerisindeki entegrasyonu arttırılmalıdır.

- Teknolojik gelişmeler 1şığında güç sistemi otomasyonları ve güç ekipmanları güncellenmelidir.

- Elektrik üretimi ve tüketimi dengesinin sürekliliğini sağlamak için düzenli bir enerji yönetimi sistemi geliştirilmelidir.

- Herhangi bir sistem anormalliği karşısında arıza tanımlaması yaparak arızayı ortadan kaldırabilecek işletme uzmanlığı ve farkındalığına sahip personel yetiştirmeli ve belli aralıklarla da eğitim verilmelidir.

- Düşük frekansta yük atma planlarını revize ederken, yük atma sırasında olası gerilim değişimlerini dikkate alarak, yük katılım miktarının yeniden değerlendirilmelidir.

Ana iletim hatları için mevcut mesafe koruma ayarları analizi ile ilgili SCADA sistem veri tabanıyla koordinasyon sağlanılmalıdır [6, 7, 9, 13, 30, 32].

\section{Sonuçlar}

Bilimsel ve teknik çalışmalar sayesinde güç sistemleri elektrik kesintilerine karşı sağlam bir yapıya gelmiş olsa bile büyük ölçekli kesinti riskleri her zaman var olmaya devam edecektir. Bu noktada geçmişte meydan gelmiş elektrik kesintilerinin kapsamlı bir şekilde analiz edilmesi kesinti risklerini en aza indirgeyebilecek önlemler alınması açısından son derece önemlidir. Özellikle mevcut güç sistemlerinin, değişken yapılı yenilenebilir enerji entegrasyonunda önemli artışların olması, akıllı şebekelerin hızla gelişmesi ve ortaya çıkan tekniklerin geniş çapta uygulanmasıyla birlikte karmaşık siber-fiziksel sistemler haline dönüşecektir. Bu durum ise güç sistemlerinin, yaygın bir kesintiye neden olma yeteneğine sahip birçok yeni faktör içermesine neden olacaktır. Yapılan bu çalışmada bugüne kadar yaşanan büyük ölçekli elektrik kesintileri etkili olduğu alanlar ve insan sayısı bakımından incelenmiştir. Kesintilerin daha iyi anlaşılabilmesi için örnek güç sistemi üzerinden çeşitli senaryolar oluşturularak güç sistemi kesintilerinin benzetimi yapılmışıtır. Yapılan benzetim çalışmaları sonucunda sistemdeki aşırı yüklü hatlarda ve üretimin yüksek olduğu jeneratörlerde meydana gelebilecek arızaların sistemin tamamını etkileyecek kesintilere neden olduğu gözlemlenmiş̧ir. Çalışmanın son aşamada ise 
kesintilere ilişkin veriler doğrultusunda meydana gelen sürecin ön koşulları da dâhil olmak üzere neden sonuç ilişkisi analiz edilerek alınabilecek tedbirler hakkında önerilerde bulunulmuştur.

\section{Teşekkür}

Bu çalışma İnönü Üniversitesi Bilimsel Araştırma Projeleri Koordinasyon birimince desteklenmiştir. Proje Numarası: 745 .

\section{Kaynaklar}

[1] Turan, M.T. 2014. Akıllı Şebekelerde Arıza Analizi ve Koruma. Yüksek lisans Tezi, Yıldız Teknik Üniversitesi, Fen Bilimleri Enstitüsü, İstanbul.

[2] Yan R., Masood N.A., Saha T.K., Bai F., Gu H. 2018. The Anatomy of the 2016 South Australia Blackout: A Catastrophic Event in a High Renewable Network. IEEE Transactions on Power Systems, pp: 1-1.

[3] Polat S., Şekerci H. 2013. Dünyada ve Ülkemizde Önemli Elektrik Çöküntüleri. III. Elektrik Tesisat Ulusal Kongre ve Sergisi, 12s. İzmir.

[4] Chakraborty N.C., Banerji A., Biswas S.K. 2015. Survey on Major Blackouts Analysis and Prevention Methodologies. Michael Faraday IET International Summit 2015, pp: 297-302.

[5] Wu Y.K., Chang S.M., Hu Y.L. 2017. Literature Review of Power System Blackouts. Energy Procedia, 141: 428-431.

[6] Bo Z., Shaojie O., Jianhua Z., Hui S., Geng W., Ming Z. 2015. An Analysis of Previous Blackouts in The World: Lessons For China's Power Industry. Renewable and Sustainable Energy Reviews, 42: 1151-1163.

[7] Veloza O.P., Santamaria F. 2016. Analysis of Major Blackouts from 2003 to 2015: Classification of İncidents and Review of Main Causes. The Electricity Journal, 29 (7): 42-49.

[8] Zalostiba D., Barkans J. 2011. Blackout of A Power System: How to Avert It Without Staff Participation? 2011 International Conference on Advanced Power System Automation and Protection, pp: 42-48, Beijing.

[9] Rahman K.M.J., Munnee M.M., Khan S. 2016. Largest Blackouts Around The World: Trends and Data Analyses. 2016 IEEE International WIE Conference on Electrical and Computer Engineering (WIECON-ECE), pp: 155-159, Pune.

[10] UCTE-Final Report of the Investigation Committee on the 28 September 2003 Blackout in Italy. http://www.rae.gr/old/cases/C13/italy/UCTE_rept.pdf(Erişim tarihi: 21.05.2018).

[11] Final Report System Disturbance on 4 November 2006. https://www.entsoe.eu/fileadmin/user_upload/_library/publications/ce/otherreports/FinalReport.pdf (Erişim tarihi: 21.05.2018).

[12] Reliability Standards for the Bulk Electric Systems of North America. https://www.nerc.com/pa/Stand/Reliability\%20Standards\%20Complete\%20Set/RSCompleteSet. pdf (Erişim tarihi: 21.05.2018).

[13] Report on Blackout in Turkey on 31st March 2015. https://docstore.entsoe.eu/Documents/SOC\%20documents/Regional_Groups_Continental_Europ e/20150921_Black_Out_Report_v10_w.pdf (Erişim tarihi: 21.05.2018).

[14] Küfeoğlu S., Lehtonen M. 2015. Interruption Costs of Service Sector Electricity Customers, A Hybrid Approach. International Journal of Electrical Power \& Energy Systems, 64: 588-595.

[15] Kariuki K.K., Allan R.N. 1996. Factors Affecting Customer Outage Costs Due to Electric Service Interruptions. Transmission and Distribution IEE Proceedings - Generation, 143 (6): 521-528.

[16] Park H. 2010. The Social Structure of Large Scale Blackouts Changing Environment. Ph.D., Institutional Imbalance and Unresponsive Organizations, the State University of New Jersey, New Jersey.

[17] Atputharajah A., Saha T.K. 2009. Power System Blackouts - Literature Review. 2009 International Conference on Industrial and Information Systems (ICIIS), pp 460-465, Sri Lanka.

[18] Saini A.K. 2014. Benefit-Function of Two-Identical Cold Standby System Subject to Failure due to Power Outage and Human Errors, International Journal of Electrical, Electronics and Computer Systems (IJEECS), 2: 8-9. 
[19] Liu Y., Fan R., Terzija V. 2016. Power System Restoration: A Literature Review from 2006 to 2016. Journal of Modern Power Systems and Clean Energy, 4 (3): 332-341.

[20] Slezak M. 2016. South Australia's Blackout Explained (and no, renewables aren't to blame), https://www.theguardian.com/australia-news/2016 (Erişim tarihi: 24.12.2018).

[21] Power Returning After Massive Outage Hits Puerto Rico CNN. https://edition.cnn.com/2018/04/12/us/puerto-rico-power-outage/index.html. (Erişim tarihi: 29.12.2018).

[22] Oral B., Dönmez F. 2008. Analysis of Disturbances in Large Power Systems: Case Study of the 1999 Marmara Earthquake. 2008 Power Quality and Supply Reliability Conference, pp: 163-167. Estonia.

[23] Yoldaş B.Y., Kekezoğlu B., Ayhancı C. 2017. Blackout and Blackstart on Power Systems. Pressacademia, 5 (1): 190-197.

[24] İTÜ Mezunları Derneği. http://www.itumd.org.tr (Erişim tarihi: 30.06.2018).

[25] Bozkurt Ö.Ö., Tayşi Z.C., Biricik G. 2015. Power Load Forecast System for Turkish Electric Market. 2015 23nd Signal Processing and Communications Applications Conference (SIU), pp: 569-572, Malatya.

[26] Demirel Ö., Kakilli A., Tektaş M. 2010. ANFIS VE ARMA Modelleri ile Elektrik Enerjisi Yük Tahmini. Gazi Üniversitesi Mühendislik-Mimarlık Fakültesi Dergisi, 25 (3): 601-610.

[27] Staszewski Ł., Rebizant W. 2018. DLR-Supported Overcurrent Line Protection For Blackout Prevention. Electric Power Systems Research, 155: 104-110.

[28] Kamali S., Amraee T. 2017. Blackout Prediction in Interconnected Electric Energy Systems Considering Generation Re-Dispatch and Energy Curtailment. Applied Energy, 187: 50-61.

[29] Çınar M., Kaygusuz A. 2018. Self-Healing In Smart Grid: A Review. Bitlis Eren Üniversitesi Fen Bilimleri Dergisi, 7 (2): 492-503.

[30] Tuttokmağ Ö., Kaygusuz A. 2017. Investigation of System Stability in Power Systems Containing Renewable Energy Sources. 8 th International Advanced Technologies Symposium, pp: 37273732, Elazı̆g.

[31] Kaygusuz A., Keleş C., Tuttokmă̆ Ö., Alagöz B.B. 2018. Possible Contributions of Smart Grids to Regional Development of Countries. International Artificial Intelligence Data Processing Symposium. Malatya.

[32] Tuttokmağı Ö., Kaygusuz A. 2019. Transient Stability Analysis of a Power System with Distributed Generation Penetration. 7.Uluslararası İstanbul Akıllı Şebekler ve Şehirler Kongresi (ICSG), İstanbul. 